\title{
Using the DOSE index to predict changes in health status of patients with COPD: a prospective cohort study
}

\author{
Myrte Rolink', Wouter van Dijk1, Saskia van den Haak-Rongen², Willem Pieters², \\ Tjard Schermer', *Lisette van den Bemt ${ }^{1}$ \\ Radboud University Nijmegen Medical Centre, Department of Primary and Community Care Nijmegen, The Netherlands \\ 2 QUARTZ Integrated Care Support Service, Helmond, The Netherlands
}

Received 29th October 2012; revised 10th December 2012; accepted 23rd December 2012; online 28th March 2013

\begin{abstract}
Background: The severity of chronic obstructive pulmonary disease (COPD) should not be based on the level of airflow limitation alone. A multicomponent index such as the DOSE index (dyspnoea score (D), level of airflow obstruction (O), current smoking status (S), and exacerbations $(E)$ ) has the potential to predict important future outcomes in patients with COPD more effectively than the forced expiratory volume in one second. Health status deterioration should be prevented in COPD patients.
\end{abstract}

Aims: To investigate whether the DOSE index can predict which patients are at risk of a clinically relevant change in health status.

Methods: A prospective cohort study was performed using data from primary and secondary care. The DOSE score was determined at baseline and the 2-year change in the Clinical COPD Questionnaire (CCQ) score was calculated. Linear regression analysis was performed for the effect of a high DOSE score $(\geq 4)$ on the change in CCQ score.

Results: The study population consisted of 209 patients (112 patients from primary care). Overall, a high DOSE score was a significant predictor of a change in CCQ score after 2 years $(0.41,95 \% \mathrm{Cl} 0.13$ to 0.70$)$, particularly in primary care patients.

Conclusions: A DOSE score of $\geq 4$ has the ability to identify COPD patients with a greater risk of future worsening in health status.

(C) 2013 Primary Care Respiratory Society UK. All rights reserved.

M Rolink et al. Prim Care Respir J 2013; 22(2): 169-174

http://dx.doi.org/10.4104/pcrj.2013.00033

Keywords COPD, primary care, secondary care, health status, DOSE index

See linked editorial by Sundh et al. on pg 142

The full version of this paper, with online appendices,

is available online at www.thepcrj.org

\section{Introduction}

According to World Health Organization estimates of 2004, 64 million people worldwide have chronic obstructive pulmonary disease (COPD). ${ }^{1}$ COPD is not curable and, because of its chronic nature, it has a substantial impact on patient's health and well-being. COPD is characterised by persistent airflow obstruction, and the level of airflow obstruction is usually expressed as the forced expiratory volume in one second $\left(\mathrm{FEV}_{1}\right)$ as percentage of predicted. ${ }^{2} \mathrm{FEV}_{1}$ has been used for classification of COPD severity for decades because of its reproductive and objective measurement using spirometry and its significant relationship with mortality. ${ }^{2-4}$ However, COPD is not just a pulmonary disease; it is also associated with systemic manifestations and co-morbid conditions. ${ }^{5-7}$ These extrapulmonary effects have an impact on a patient's daily life, prognosis, and mortality. ${ }^{8,9}$ However, they do not correlate well with $\mathrm{FEV}_{1} \cdot{ }^{10}$ Several multidimensional grading systems have therefore emerged which should enable better prediction of future morbidity and mortality risk in COPD patients than FEV 1 alone.." Jones et al. developed and validated the 'DOSE' index using data from primary care patients with COPD. ${ }^{12}$ The DOSE index is a four-component index that includes dyspnoea score (D), level of airflow obstruction (O), current smoking status (S), and annual exacerbation rate (E). A DOSE score of $\geq 4$ was associated with an increased risk of hospitalisation, respiratory failure, and mortality. ${ }^{12,13}$

In their study Jones et al. also found an association between the DOSE index and patients' health status, but they only looked at cross-sectional associations. ${ }^{12}$ It is therefore currently unknown if the DOSE index is also able to predict which patients with COPD are at high risk of a significant decline in health status.

\footnotetext{
* Corresponding author: Dr Lisette van den Bemt PhD, Radboud University Nijmegen Medical Centre, Department of Primary and Community Care, P.O. Box 9101, 6500 HB Nijmegen, The Netherlands. Tel: 0031-243619588 E-mail: L.vandenbemt@elg.umcn.nl
} 
The aim of our study was to investigate if the DOSE index predicts clinically relevant changes in health status in a cohort consisting of primary and secondary care patients with COPD who were followed for two years.

\section{Methods}

\section{Study design}

We performed a cohort study based on prospectively collected routine care data available from the Quartz Integrated Care Support Service in Helmond, The Netherlands. Our objective was to establish the predictive value of a DOSE score of $\geq 4$ on change in the Clinical COPD Questionnaire (CCQ) score. Subgroup analyses with primary or secondary care patients separately were done to evaluate whether the DOSE index has a predictive value in both settings.

\section{Study population}

In 2005 the Quartz service initiated an integrated COPD disease management programme which started by making an inventory of the COPD patient population in the city of Helmond and surroundings. All 38 general practices that are supported by Quartz as well as the pulmonologists of the local Elkerliek hospital provided lists of all their COPD patients. Patients indicated the principal care provider for their COPD (i.e. their general practitioner (GP) or a pulmonologist) at the start of the programme. Informed consent was obtained from patients before data collection started. The protocol was submitted to the local medical ethics committee who considered that a formal review was not obligatory.

\section{Patient selection}

Patients were selected for the current analysis if they were aged $\geq 40$ years and had a prebronchodilator $\mathrm{FEV}_{1}$ /forced vital capacity (FVC) ratio of $<0.7$. Patients with missing data or no recent lung function test (i.e. $\geq 1$ year before the patient's screening date) were excluded from further analysis.

\section{DOSE index}

Baseline data were used to calculate patients' DOSE scores according to the schedule shown in Table 1. The total DOSE score is the sum of the four components and has a range of $0-8$, with a higher score representing more severe disease. ${ }^{12}$

\section{Grade of dyspnoea (D)}

The modified Medical Research Council (MRC) scale is an instrument to quantify a patient's perceived exertional dyspnoea. ${ }^{14}$ Patients are instructed to select the statement that applies to them most on a scale of $0-4$. A higher score on the MRC scale represents a higher level of dyspnoea.

Table 1. DOSE index scoring system

\begin{tabular}{lllll}
\multicolumn{4}{c}{ DOSE index point } \\
& 0 & 1 & 2 & 3 \\
\hline D MRC dyspnoea score scale & $0-1$ & 2 & 3 & 4 \\
\hline O Obstruction $\mathrm{FEV}_{1} \%$ predicted & $\geq 50 \%$ & $30-49 \%$ & $<30 \%$ \\
\hline S Current smoking status & Non-smoker & Smoker \\
\hline E Exacerbations/year & $0-1$ & $2-3$ & $>3$ \\
\hline MRC=Medical Research Council, $\mathrm{FEV}_{1} \%$ : forced expiratory volume in \\
1 second percentage of predicted value.
\end{tabular}

\section{Lung function (O)}

$\mathrm{FEV}_{1}$ and FVC were measured using Welch Allyn PC-based SpiroPerfect spirometer (Delft, The Netherlands) or Jaeger J62 Body Box in routine care. If data from a recent lung function assessment were available, no new spirometric examination was requested as part of the COPD population inventory. In our real-life study, many postbronchodilator values were missing so we used prebronchodilator $\mathrm{FEV}_{1}$ and $\mathrm{FVC}$ values (i.e. prior to a controlled administration of a bronchodilator). $\mathrm{FEV}_{1}$ as a percentage of the predicted value (FEV $1 \%$ predicted) was calculated using European Community for Coal and Steel reference values. ${ }^{15}$

\section{Smoking status (S)}

Patients were asked about their current daily smoking status. Exsmoking was considered as non-current smoking.

\section{Exacerbations (E)}

Patients were asked about the number of exacerbations they had had in the past year at baseline. The definition of an exacerbation used in the integrated disease management programme matches the definition used in the development of the DOSE index. ${ }^{16}$ Along with patients' self-report, the DOSE index requires confirmation of an exacerbation with data from the medical record. In our cohort this confirmation was made by patients' self-report on healthcare contacts (i.e. contacted a physician or hospital admission with regard to an exacerbation).

\section{Health status}

Health status was measured using the CCQ, which has been developed as a COPD-specific health status measurement using data from primary and secondary care patients. ${ }^{17}$ The CCQ consists of 10 questions in three domains: symptoms, mental state, and functional state. Questions are scored on a scale of 0-6, with a higher score representing worse health status. We used the CCQ score at baseline and after two years (with a range of \pm 3 months) in our current analysis. The minimal clinical important difference (MCID) is a change in CCQ score of $\geq 0.4$ points. $^{18}$

\section{Statistical analysis}

Descriptive analyses were conducted by calculating mean and standard deviation for continuous variables (i.e. after normality testing confirmed a normal distribution) and frequency and percentages for discrete variables. Differences in patients' characteristics between primary and secondary care patients were tested by independent $t$ test or $\chi 2$ test, depending on variable characteristics.

We compared the 2-year change in CCQ score between patients with a DOSE score of $\geq 4$ and those with a score of $<4$. A univariate linear regression model was used to assess the predictive value of a high DOSE score (i.e. $<4$ points versus $\geq 4$ points) on the change in CCQ score after 2 years. Our primary interest was the unstandardised regression coefficient $(B)$ of a high DOSE score on change in CCQ score, as this information represents the value of the DOSE index for daily care. In a next step we corrected the regression analysis for the baseline CCQ score. Next, we added potential confounders as reported in the literature: body mass index (BMI), age, gender, and educational level (defined as low, middle, or high in accordance with the CBS Statistics Netherlands criteria, 2012). ${ }^{19}$ The same analyses were carried out for primary care and secondary 
Figure 1. Flow chart of patient selection

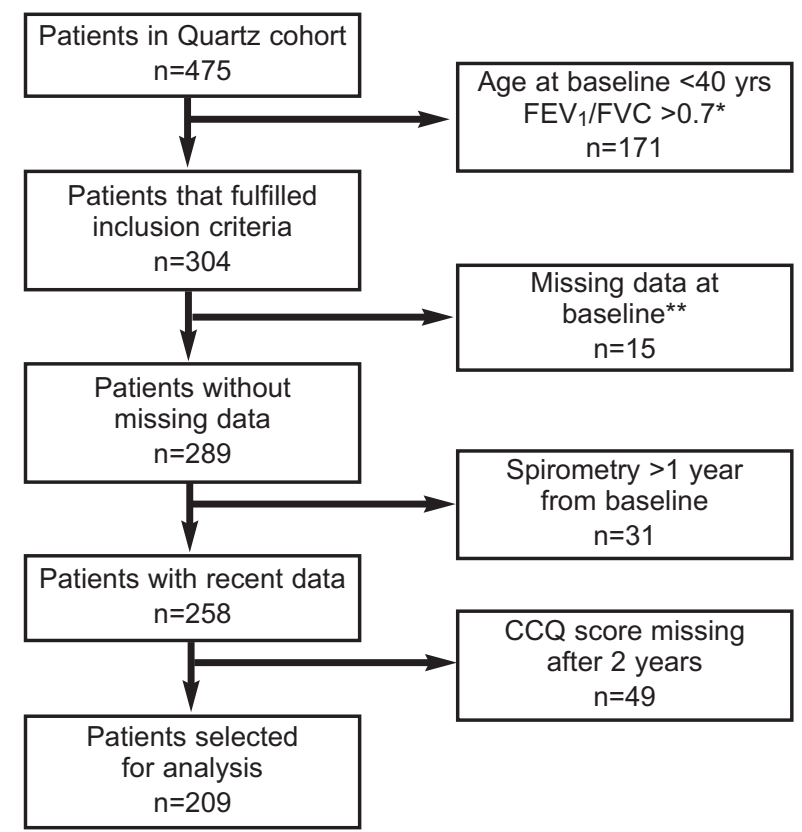

* forced expiratory volume in one second $\left(\mathrm{FEV}_{1}\right) /$ forced vital capacity (FVC) without administration of a bronchodilator

** 1 missing value of smoking status

1 missing value of CCQ score at baseline

13 missing values for educational level care patients separately.

In order to compare multidimensional (DOSE-based) with unidimensional ( $\mathrm{FEV}_{1}$-based) classification of COPD severity, we calculated C-statistics (ranging from 0.5 to 1.0 ) to determine the predictive value of a DOSE score of $\geq 4$ and $<50 \% \mathrm{FEV}_{1} \%$ predicted for a MCID change in CCQ score.

Data management and analysis were performed using SPSS Version 18.0 (Chicago, USA). For all statistical tests, $\mathrm{p} \leq 0.05$ was considered statistically significant.

\section{Results}

\section{Baseline characteristics}

Patient selection is shown in Figure 1. The baseline characteristics of the 209 selected patients are reported in Table 2. The characteristics of the selected patients did not differ from excluded patients (see Appendix 1, available online at www.thepcrj.org). Overall, $65.1 \%$ of patients were male and their average age was 66 years. The mean (SD) DOSE score was 1.55 (1.58). The distribution of the DOSE index in the total study population is shown in Figure 2. Statistically significant differences in characteristics between the secondary and primary care patients were more males (72\% vs. 64\%), a higher DOSE score, and a higher CCQ score (Table 2). Although the mean FEV $1 \%$ predicted and the GOLD classification did not differ, mean $\mathrm{FEV}_{1} / \mathrm{FVC}$ was considerably lower in secondary care patients (50.6 vs. 56.2).

Health status

Associations between the change in CCQ score and baseline DOSE index are shown in Table 3. For the total study population a high DOSE score (i.e. $\geq 4$ points) was a significant predictor of a change in CCQ score after 2 years $(0.41,95 \% \mathrm{Cl} 0.13$ to $0.70, p=0.005)$. In

Table 2. Baseline characteristics of COPD study population from primary and secondary care

\begin{tabular}{|c|c|c|c|c|c|c|}
\hline & \multicolumn{2}{|c|}{ Primary care } & \multicolumn{2}{|c|}{ Secondary care } & \multicolumn{2}{|c|}{ Total } \\
\hline Subjects, n (\%) & \multicolumn{2}{|c|}{$112(54)$} & \multicolumn{2}{|c|}{$97(46)$} & \multicolumn{2}{|c|}{209} \\
\hline Age (years) & 65.5 & $(9.8)$ & 66.5 & (9.4) & 66.0 & $(4.4)$ \\
\hline Gender (male), n (\%) & 64 & $(57.1)$ & $72^{*}$ & $(74.2)$ & 136 & $(65.1)$ \\
\hline \multicolumn{7}{|l|}{ Education ${ }^{\dagger}, \mathrm{n}(\%)$} \\
\hline Low & 77 & $(68.8)$ & 68 & $(70.1)$ & 145 & $(69.4)$ \\
\hline Middle & 29 & $(25.9)$ & 25 & $(25.8)$ & 54 & $(25.8)$ \\
\hline High & 6 & $(5.4)$ & 4 & $(4.1)$ & 10 & $(4.8)$ \\
\hline $\mathrm{BMI} \leq 21 \mathrm{~kg} / \mathrm{m}^{2}, \mathrm{n}(\%)$ & 13 & $(11.6)$ & 7 & $(7.2)$ & 20 & (9.5) \\
\hline $\mathrm{FEV}_{1} \%$ predicted & 59.1 & $(16.4)$ & 54.6 & $(19.5)$ & 57.0 & $(18.0)$ \\
\hline $\mathrm{FEV}_{1} / \mathrm{FVC}$ & 56.2 & $(11.2)$ & $50.6^{* *}$ & $(11.0)$ & 53.6 & $(11.1)$ \\
\hline GOLD $1(\%)$ & 11 & (9.8) & 7 & $(7.2)$ & 18 & (8.6) \\
\hline GOLD 2 (\%) & 70 & $(62.5)$ & 49 & $(50.5)$ & 119 & $(56.9)$ \\
\hline GOLD 3 (\%) & 27 & $(24.1)$ & 32 & $(33.0)$ & 59 & $(28.2)$ \\
\hline GOLD 4 (\%) & 4 & (3.6) & 9 & $(9.3)$ & 13 & $(6.2)$ \\
\hline Patients with exacerbation in past 12 months, $\mathrm{n}(\%)$ & 20 & $(17.9)$ & $32 * *$ & $(33.0)$ & 52 & $(24.9)$ \\
\hline DOSE score (points) & 1.4 & $(1.5)$ & $1.8^{*}$ & $(1.7)$ & 1.6 & $(1.6)$ \\
\hline DOSE score $(\geq 4), \mathrm{n}(\%)$ & 10 & $(8.9)$ & 15 & $(15.5)$ & 25 & $(12.0)$ \\
\hline Total CCQ score & 1.5 & $(1.1)$ & $2.2 * *$ & $(1.2)$ & 1.9 & $(1.1)$ \\
\hline
\end{tabular}




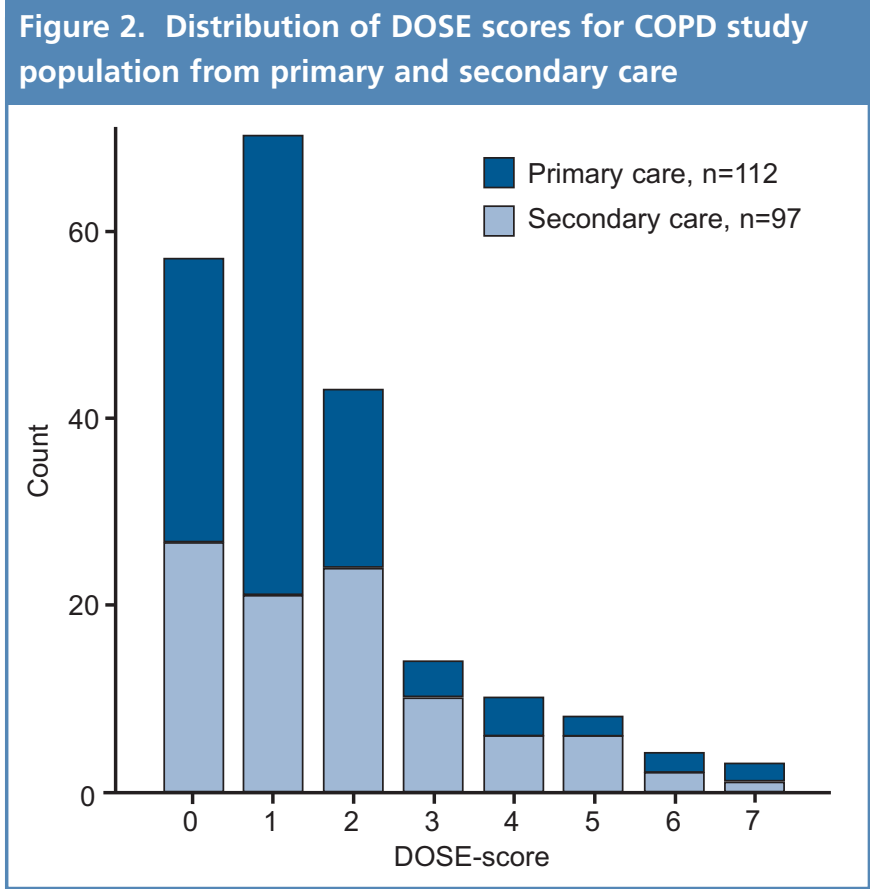

primary care, patients with a high DOSE score showed on average a 0.51 (95\% Cl 0.13 to $0.89, p=0.009$ ) higher CCQ score after 2 years than patients with a low DOSE score. In secondary care patients the CCQ score was 0.35 (95\% Cl -0.09 to $0.78, p=0.114)$ higher in patients with a high DOSE score. After correction for covariates, a high DOSE index was a significant predictor in both primary and secondary care settings (Table 3).

Full regression models including the potential confounders and standardised beta coefficients are shown in Appendix 2, available online at www.thepcrj.org.

The C-statistic for the ability of a DOSE score of $\geq 4$ to predict significant worsening in the CCQ score (i.e. CCQ score $\geq 0.4$ point change) after 2 years was $0.62(95 \% \mathrm{Cl} 0.50$ to $0.74, \mathrm{p}=0.054)$ compared with 0.53 for $\mathrm{FEV}_{1}<50 \%$ predicted alone $(95 \% \mathrm{Cl} 0.45$ to $0.51, p=0.512$ ).

\section{Disaussion}

In this study we investigated if, in routine patient care, the DOSE index can predict clinically relevant changes in health status as measured with the CCQ. We found that the association between a high DOSE score (i.e. 24 ) and 2-year change in the CCQ score was statistically significant and clinically relevant (i.e. it exceeded the MCID of the CCQ), especially for patients managed in primary care. The C-statistic value of a high DOSE score to predict a relevant change in the CCQ score was higher than the predictive capacity of $\mathrm{FEV}_{1} \%$ predicted alone, but still rather low (0.62).

\section{Strengths and limitations of the study}

The strength of our study is the unique and representative cohort of patients from both primary and secondary care with a 2-year followup, which also allowed us to look at specific differences between these two groups of patients. In the Netherlands, all inhabitants are registered at a general practice and the cohort consists of full practice screening (i.e. unrestrained by the principal care provider). Moreover, the cohort represents a 'real-life' COPD patient population because data were collected within the context of a healthcare improvement project and therefore were not limited to COPD patients who were willing to participate in a scientific study.

There were some limitations to using data from this real-life cohort. The most important limitation was that many postbronchodilator values were missing and we had to use prebronchodilator values instead. Because of this, $\mathrm{FEV}_{1} \%$ predicted may have been over-rated in patients with partly reversible airflow obstruction, which may have resulted in lower DOSE scores compared with the original DOSE scoring system that requires postbronchodilator $\mathrm{FEV}_{1} \%$ predicted. The $\mathrm{FEV}_{1}$ of some patients might have improved after administering a bronchodilatator. ${ }^{20}$ On the other hand, Mannino et al. showed in a research setting that pre- and postbronchodilator values predict longterm outcomes in a similar way. ${ }^{21}$

Another deviation from the original DOSE scoring system is that we could not confirm exacerbations through examination of patients' medical records but had to base this on confirmation by patients who recalled that they had been seen by a healthcare professional for an exacerbation that year. Although this is not in concordance with the original DOSE scoring system, a recent study showed that COPD patients can accurately recall the number of exacerbations they have experienced in the past year. ${ }^{22}$ Moreover, reliable information on diagnoses of important co-morbid conditions like cardiovascular diseases was not available.

We compared the predictive capacity of the multidimensional DOSE index with the unidimensional ( $F E V_{1}$-based) COPD severity

Table 3. Linear regression on average 2 -year change in CCQ score for baseline DOSE score $>4$ and DOSE score $<4$ before and after correction for covariates

\begin{tabular}{|c|c|c|c|}
\hline Variable & $\begin{array}{l}\text { Model } 1 \\
\beta(95 \% \mathrm{Cl}) \\
\end{array}$ & $\begin{array}{l}\text { Model } 2 \\
\beta(95 \% \mathrm{Cl}) \\
\end{array}$ & $\begin{array}{l}\text { Model } 3 \\
\beta(95 \% \mathrm{Cl}) \\
\end{array}$ \\
\hline$\Delta C C Q$ score, total study population $(n=209)$ & $0.41^{* *}(0.13$ to 0.70$)$ & $0.73 * *(0.42$ to 1.03$)$ & $0.68^{* *}(0.36$ to 1.00$)$ \\
\hline$\Delta \mathrm{CCQ}$ score, primary care $(\mathrm{n}=112)$ & $0.51 * *(0.13$ to 0.89$)$ & $0.60 * *(0.18$ to 1.02$)$ & $0.45 *(0.02$ to 0.88$)$ \\
\hline$\Delta$ CCQ score, secondary care $(n=97)$ & $0.35(-0.09$ to 0.78$)$ & $0.86^{* *}(0.41$ to 1.31$)$ & $0.86^{* *}(0.39$ to 1.34$)$ \\
\hline \multicolumn{4}{|l|}{$\beta=$ unstandardised coefficient } \\
\hline \multicolumn{4}{|c|}{$C C Q=C$ linical COPD Questionnaire (scored on a scale of $0-6$ ), $\Delta C C Q=$ difference in $C C Q$ score between baseline and 2-year follow-up. ${ }^{*} p \leq 0.05,{ }^{* *} p \leq 0.01$. } \\
\hline
\end{tabular}


classification in our study. The $\mathrm{FEV}_{1} \%$ predicted classification is also part of the DOSE index, so this comparison must be seen as a comparison of the DOSE index with one of its elements.

The characteristics of primary and secondary care patients did not show statistically significant differences in GOLD stage despite the fact that current guidelines require treatment of COPD patients with GOLD stage 3 and 4 in secondary care and patients with controlled COPD in GOLD stage 1 and 2 in primary care. ${ }^{23}$ This indicates that referral to secondary care by GPs is not only determined by $F E V_{1}$, which is what one would expect.

\section{Interpretation of findings in relation to previously published work}

Previous research revealed that a DOSE score of $\geq 4$ was associated with an increased risk of hospitalisation, respiratory failure, and mortality. ${ }^{12,13}$ This study shows that a high DOSE score is also associated with a clinically relevant change in health status. Preserving health status and reducing future risks are important treatment goals in COPD. A high DOSE score seems able to detect patients at risk of failing both these goals.

Implications for future research, policy and practice We noted that the DOSE index does not distinguish between mild, moderate, and severe exacerbations. A patient with one single severe exacerbation that requires hospital admission will have a lower DOSE score than a patient with two exacerbations without hospital admission or medication change. It is likely that one severe exacerbation will have a greater impact on a patient's quality of life than two mild exacerbations but, in the current scoring system, this is not reflected in a higher DOSE score. It would be interesting to see how different exacerbation definitions impact on the predictive capacity of the DOSE index.

In our study we evaluated the effect of the baseline DOSE index score on a change in CCQ score during 2 years of follow-up. It would be interesting to take a closer look at the correlation between the DOSE index and the CCQ score - for example, whether a change in DOSE score over time is also reflected in a change in CCQ score. We did not have all the essential data to reassess the DOSE score after 2 years, but this would provide additional information on the predictive value and responsiveness of the DOSE index.

To be clinically relevant, the ability of a DOSE score of $\geq 4$ to identify patients with a greater risk of future worsening of their health status should be associated with disease management options that result in a relevant improvement in the patient's disease state or prognosis. Chavannes et al. reported that integrated care management resulted in the most profound improvement in CCQ score in primary care patients with an MRC score of $>2 .{ }^{24}$ The only study in which the DOSE score has been used for identification and case management of high-risk COPD patients was too small to show a statistically significant difference. ${ }^{25}$

\section{Condusions}

In daily care, a DOSE score of $\geq 4$ has the ability to identify patients with a greater risk of future worsening in COPD-specific health status in the following 2 years, particularly in primary care. Research should focus on the evaluation of disease management strategies to diminish these negative outcomes in COPD patients with high DOSE scores.
Handling editor Niels Chavannes Statistical review Gopal Netuveli

Acknowledgements The authors would like to thank the employees of the Quartz Integrated Care Support Service who were directly or indirectly involved in the disease management programme and therefore responsible for the collection of the data presented in this article. They are also very grateful to all the participating patients, practice assistants, and general practitioners.

Conflicts of interest The authors declare that they have no conflicts of interest in relation to this article.

Contributorship SvdH, WP: conception and design of the disease management programme. MR, LvdB, TS: conception and design of the study. LvdB, SvdH, TS: supervision of the study. MR, LvdB: data cleaning and analysis, interpretation of results. MR, WvD, TS, LvdB: drafting the manuscript. All authors approved the intellectual content. $L v d B$ is the guarantor of the study.

\section{Funding None.}

\section{References}

1. World Health Organization. COPD factsheet. 2008. Available from: http://www.who.int/respiratory/copd/en/index.html (accessed 2 May 2012).

2. Global Initiative for Chronic Obstructive Lung Disease (GOLD). 2011 (updated December 2011). Available from: www.goldcopd.com (accessed 2 May 2012).

3. Fletcher $\mathrm{C}$, Peto R. The natural history of chronic airflow obstruction. Br Med $J$ 1977;1:1645-8. http://dx.doi.org/10.1136/bmj.1.6077.1645

4. Celli BR, Cote CG, Lareau SC, Meek PM. Predictors of survival in COPD: more than just the FEV1. Respir Med 2008;102:S27-S35. http://dx.doi.org/10.1016/S0954-6111(08)70005-2

5. Oga T, Tsukino M, Hajiro T, Ikeda A, Nishimura K. Predictive properties of different multidimensional staging systems in patients with chronic obstructive pulmonary disease. Int J Chron Obstruct Pulmon Dis 2011;6:521-6. http://dx.doi.org/10.2147/COPD.S24420

6. van der Molen T. Co-morbidities of COPD in primary care: frequency, relation to COPD, and treatment consequences. Prim Care Respir J 2010:19:326-34. http://dx.doi.org/10.4104/pcrj.2010.00053

7. Wouters EF. Chronic obstructive pulmonary disease. 5: Systemic effects of COPD. Thorax 2002;57:1067-70. http://dx.doi.org/10.1136/thorax.57.12.1067

8. Sin DD, Anthonisen NR, Soriano JB, Agusti AG. Mortality in COPD: role of comorbidities. Eur Respir J 2006;28:1245-57. http://dx.doi.org/10.1183/09031936.00133805

9. Tsiligianni I, Kocks J, Tzanakis N, Siafakas N, van der Molen T. Factors that influence disease-specific quality of life or health status in patients with COPD: a review and meta-analysis of Pearson correlations. Prim Care Respir J 2011;20:257-68. http://dx.doi.org/10.4104/pcri.2011.00029

10. Decramer M, Janssens W, Miravitlles M. Chronic obstructive pulmonary disease Lancet 2012;379:1341-51. http://dx.doi.org/10.1016/S0140-6736(11)60968-9

11. Dijk WD, Bemt $L$, Haak-Rongen $S$, et al. Multidimensional prognostic indices for use in COPD patient care. A systematic review. Respir Res 2011;12:151. http://dx.doi.org/10.1186/1465-9921-12-151

12. Jones RC, Donaldson GC, Chavannes $\mathrm{NH}$, et al. Derivation and validation of a composite index of severity in chronic obstructive pulmonary disease: the DOSE Index. Am J Respir Crit Care Med 2009;180:1189-95.

http://dx.doi.org/10.1164/rccm.200902-02710C

13. Sundh J, Janson C, Lisspers K, Stallberg B, Montgomery S. The Dyspnoea, Obstruction, Smoking, Exacerbation (DOSE) index is predictive of mortality in COPD. Prim Care Respir J 2012;21(3):295-301.http://dx.doi.org/10.4104/pcrj.2012.00054

14. Bestall JC, Paul EA, Garrod R, Garnham R, Jones PW, Wedzicha JA. Usefulness of the Medical Research Council (MRC) dyspnoea scale as a measure of disability in patients with chronic obstructive pulmonary disease. Thorax 1999;54:581-6. http://dx.doi.org/10.1136/thx.54.7.581

15. Quanjer PH, Tammeling GJ, Cotes JE, Pedersen OF, Peslin R, Yernault JC. Lung volumes and forced ventilatory flows. Report Working Party Standardization of Lung Function Tests, European Community for Steel and Coal. Official Statement of the European Respiratory Society. Eur Respir J Suppl 1993;16:5-40.

16. National Institute for Clinical Excellence. Chronic obstructive pulmonary disease: national clinical guideline for management of chronic obstructive pulmonary disease in adults in primary and secondary care. Thorax 2004:59(Suppl I):i1-232. 
17. van der Molen T, Willemse B, Schokker S, ten Hacken N, Postma D, Juniper E. Development, validity and responsiveness of the Clinical COPD Questionnaire. Health Quality of Life Outcomes 2003;1:13

http://dx.doi.org/10.1186/1477-7525-1-13

18. Kocks JW, Tuinenga MG, Uil SM, van den Berg JW, Stahl E, van der Molen T. Health status measurement in COPD: the minimal clinically important difference of the clinical COPD questionnaire. Respir Res 2006;7:62.

http://dx.doi.org/10.1186/1465-9921-7-62

19. Centraal Bureau voor de Statistiek [Internet]. Standaard Beroepenclassificatie 1992 (SBC-92) [Standard Profession Classification]. 1992 (updated 2001). Available from: http://www.cbs.nl/nl-NL/menu/methoden/classificaties/overzicht/sbc/default.htm (accessed 15 May 2012).

20. Geijer RMM, Chavannes NH, Muris JWM, I. NHG standaard Astma bij volwassenen. [Dutch College of General Practitioners guideline on adult asthma]. Huisarts Wet 2007;50:537-51.

21. Mannino DM, Diaz-Guzman E, Buist S. Pre- and post-bronchodilator lung function as predictors of mortality in the Lung Health Study. Respir Res 2011;12:136. http://dx.doi.org/10.1186/1465-9921-12-136

22. Quint JK, Donaldson GC, Hurst JR, Goldring JJ, Seemungal TR, Wedzicha JA Predictive accuracy of patient reported exacerbation frequency in chronic obstructive pulmonary disease. Eur Respir J 2011;37(3):501-07. http://dx.doi.org/10.1183/09031936.00035909

23. Smeele IJM, van Weel C, van Schayck CP, et al. NHG-Standaard COPD tweede herziening. [Dutch College of General Practitioners guideline on COPD, second revision]. Huisarts Wet 2007;50:362-79.

24. Chavannes $\mathrm{NH}$, Grijsen $\mathrm{M}$, van den $\mathrm{AM}$, et al. Integrated disease management improves one-year quality of life in primary care COPD patients: a controlled clinical trial. Prim Care Respir J 2009;18:171-6. http://dx.doi.org/10.3132/pcrj.2009.00003

25. Gruffydd-Jones K, Richman J, Jones RC, Wang X. A pilot study of identification and case management of high-risk COPD patients in a general practice. Family Pract 2010;27(5):494-8. http://dx.doi.org/10.1093/fampra/cmq045

\section{Available online at http://www.thepcrj.org}




\section{Appendix 1}

\section{Supplem entary file:}

Characteristics of paticiparts ver'sus excluded patierts

\begin{tabular}{|c|c|c|c|c|c|}
\hline & \multicolumn{2}{|c|}{ Palticiparts } & \multicolumn{2}{|c|}{ Excuded patients } & \multirow[t]{2}{*}{ P-value ${ }^{*}$} \\
\hline Subjects, number (\%) & & 209 & & 95 & \\
\hline Age (years) & 66.0 & (4.4) & 662 & $(1 \mid \beta)$ & 0.86 \\
\hline Gender (nale), number (\%) & 136 & (35.1) & 163 & $(663)$ & 0.83 \\
\hline Care provider (GP), number $(\%)$ & 112 & $(63.6)$ & 40 & $(51.1)$ & 0.75 \\
\hline Blwll $\leq 21$ kgim ${ }^{2}$, number $(\%)$ & 20 & (9.5) & 15 & $(158)$ & 0.12 \\
\hline Cument smoking, number (\%) & 78 & $(38.3)$ & $46^{+}$ & $(48.4)$ & DD8 \\
\hline FEV,\% pledicted & 57.0 & $(18.0)$ & 57.4 & $(199)$ & 0.85 \\
\hline FEVMIF VC & 53.6 & (II.1) & 558 & $(10.7)$ & 0.15 \\
\hline GOLD $1(\%)$ & 18 & (8.6) & 9 & $(05)$ & 100 \\
\hline GOLD $2(\%)$ & 110 & $(56.9)$ & 53 & $(558)$ & \\
\hline GOLD $3(\%)$ & 50 & $(28.2)$ & 27 & $(28.4)$ & \\
\hline GOLD $4(\%)$ & 13 & (6.2) & 6 & (B) & \\
\hline $\begin{array}{l}\text { Patients with exacerbation in } \\
\text { past } 12 \text { months, number (\%) }\end{array}$ & 52 & $(24.9)$ & 22 & $(232)$ & 0.75 \\
\hline DOSE scole fpoints & 1.6 & $(1.6)$ & $1.78^{+}$ & $(1 B)$ & 024 \\
\hline DOSE scole $(24)$, number $(\%)$ & 25 & $(12.0)$ & $13^{+}$ & $(13.7)$ & 0.85 \\
\hline Total CCQ scole baseline & 1.9 & (1.1) & $2.07^{+}$ & (1 22) & 0.13 \\
\hline
\end{tabular}




\section{Appendix 2}

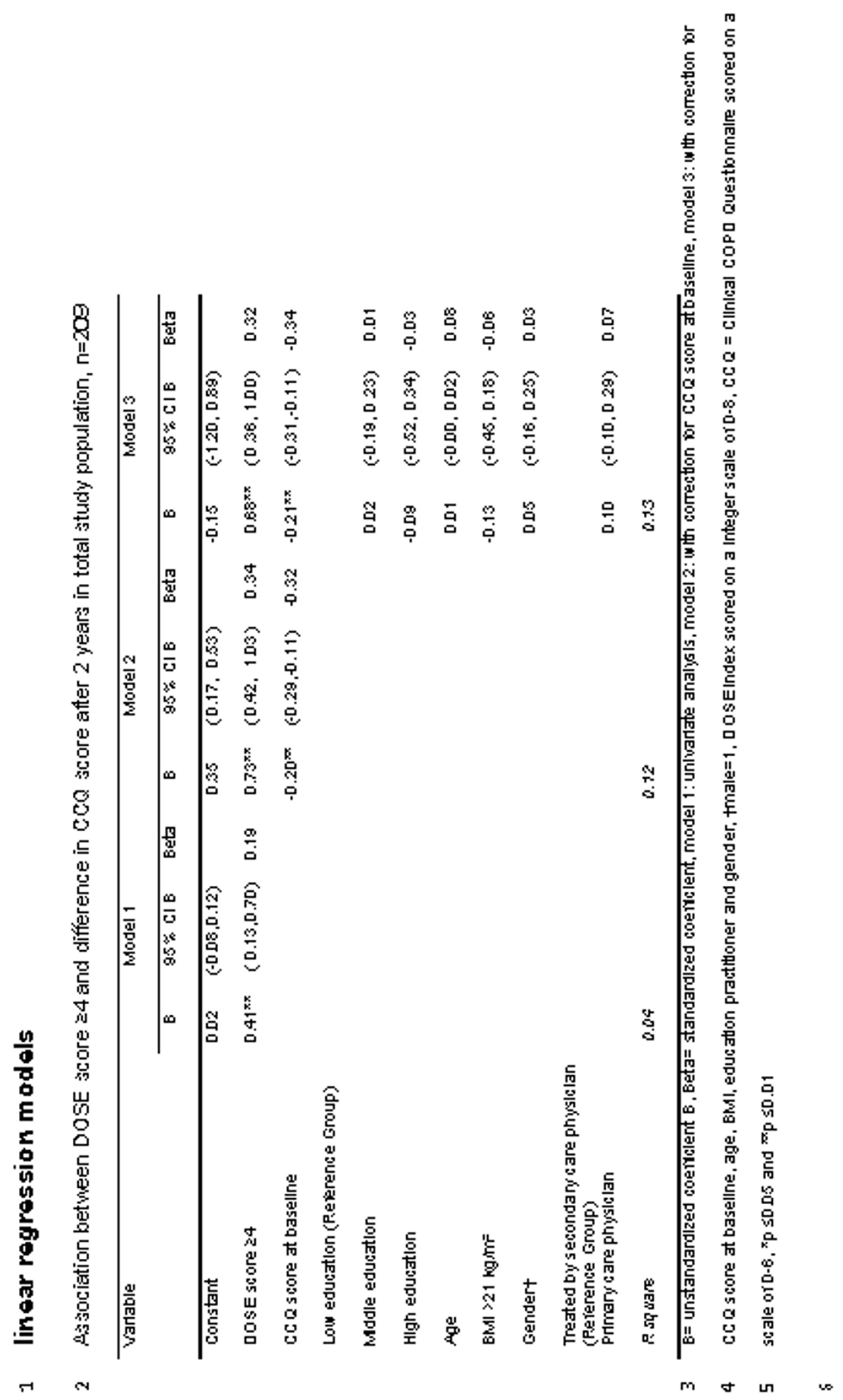




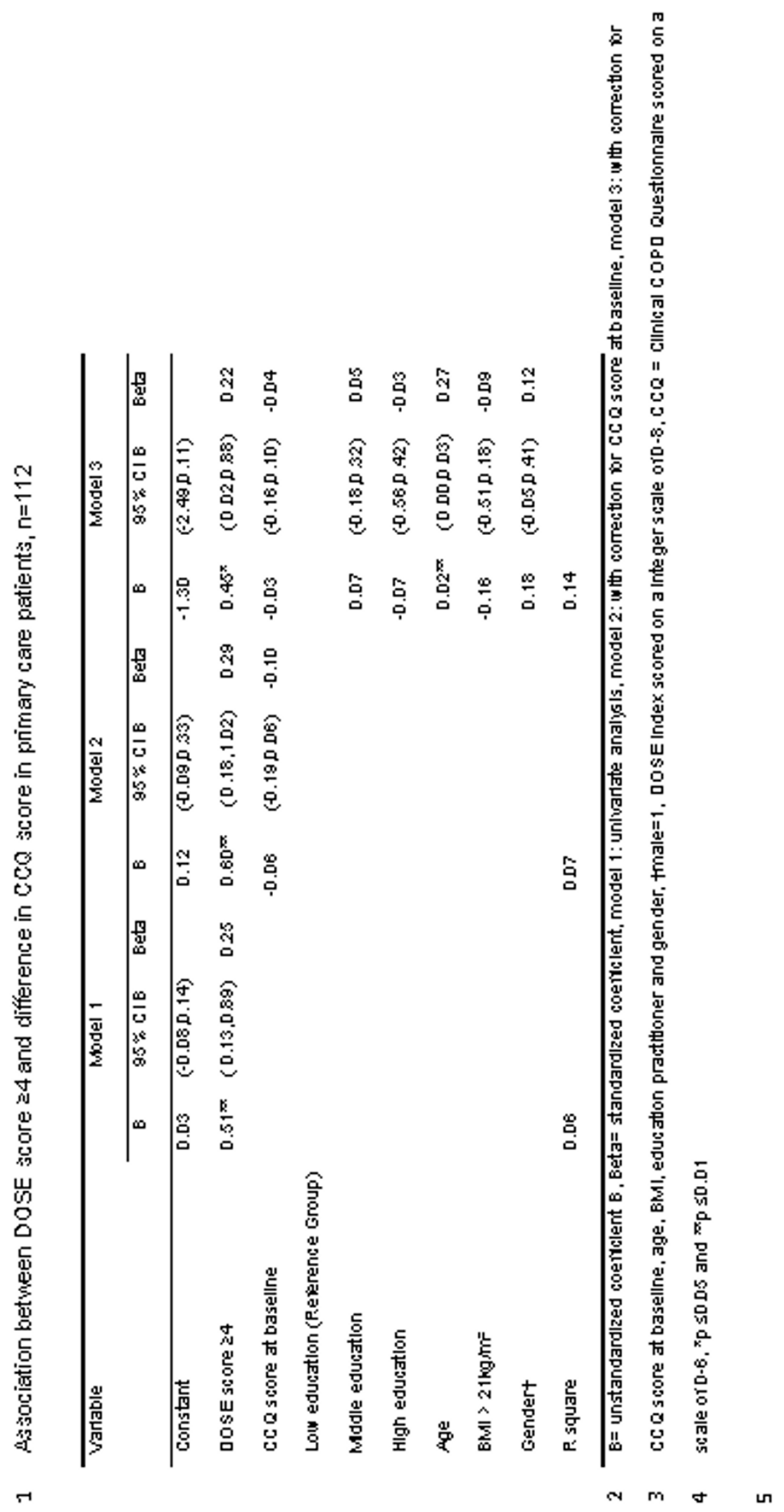




\section{Appendix 2}

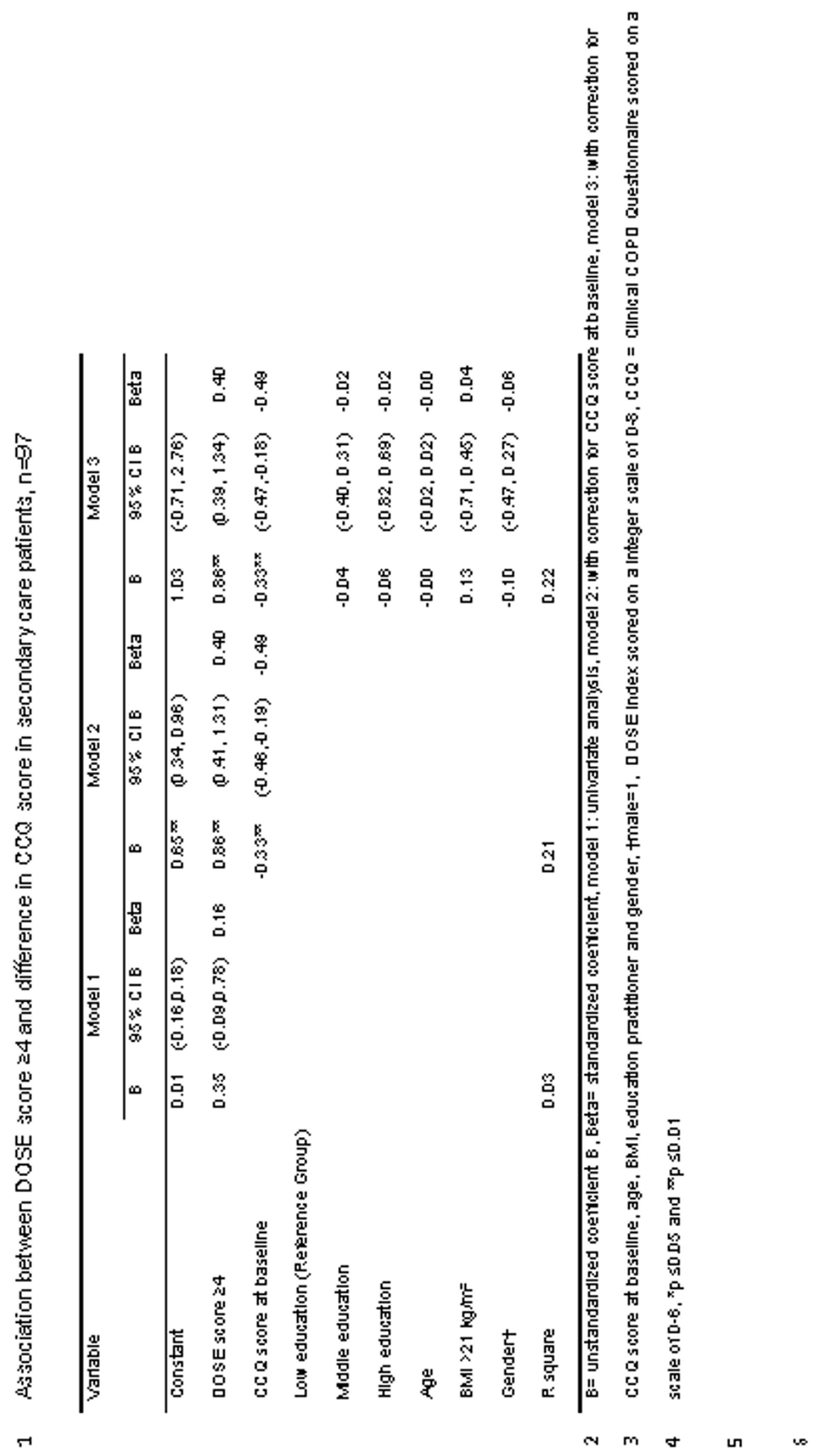

